\title{
DESAFIOS E PERSPECTIVAS PARA A AGRICULTURA FAMILIAR DO MUNICÍPIO DE RIBEIRÓPOLIS - SE
}

\section{Challenges and prospects for family farming in the municipality of Ribeirópolis - SE}

\section{Desafíos y perspectivas para la agricultura familiar del municipio de Ribeirópolis - SE}

João Ernandes Barreto Nascimento ${ }^{1}$ https://orcid.org/0000-0001-6298-957X

José Eloízio da Costa ${ }^{2}$ https://orcid.org/0000-0002-3777-5403

Fernanda Viana de Alcantara ${ }^{3}$ https://orcid.org/0000-0002-9296-8558

\begin{abstract}
1 Mestrando em Geografia (PPGeo/UESB), bolsista da Universidade Estadual do Sudoeste da Bahia (UESB) e membro do Grupo de Pesquisa Sobre Dinâmica Rural e Regional (GDRR/UFS) credenciado no CNPq. ernandes20bn@ hotmail.com

2 Docente do programa de pós-graduação da Universidade Federal de Sergipe.eloizio.npgeo@gmail.com

3 Professora do programa de pós-graduação em geografia da UESB, do departamento de Geografia da UESB e da rede estadual de ensino do Estado da Bahia.nandanpgeo@yahoo.com.br
\end{abstract}

\section{Resumo}

O objetivo deste trabalho consiste em compreender dinâmica socioeconômica que envolve a agricultura familiar do município de Ribeirópolis/SE, buscando identificar os fatores que podem ser compreendidos como atuantes na reprodução das unidades familiares deste município. Sendo assim, a partir da revisão da literatura selecionada e através das discussões em reuniões semanais realizadas no Grupo de Pesquisa sobre Dinâmica Rural e Regional (GDRR), além da coleta e análise de dados secundários, pode-se fundamentar teórico e empiricamente a pesquisa em questão, além da realização de trabalho de campo onde foram aplicados 15 questionários e realizadas entrevistas semiestruturadas. Pode-se destacar que as rendas oriundas das atividades não agrícolas, verificadas a partir do trabalho de campo, são atividades do tipo pedreiro, ajudante de serviços em geral, pintor, faxineira e marchante.

Palavras-chave: Agricultura Familiar. Pluriatividade. Desenvolvimento Rural.

\begin{abstract}
The aim of this work is to understand the spatial dynamic that involves the family farm in the municipality of Ribeirópolis/SE, with the field of analysis, seeking to identify the factors that can be understood as acting on the reproduction of family units this municipality. Thus, from the review of selected literature and through discussions at weekly meetings held in the research group on Rural and Regional Dynamics (GDRR), in addition to secondary data collection and analysis, one can substantiate theoretical and empirically research in question, in addition to conducting fieldwork where questionnaires were applied and conducted semistructured interviews. You can highlight even if rents from non-agricultural activities, scanned from the fieldwork, are activities of type Mason, General Services Assistant, painter, cleaner and marchante.
\end{abstract}

Keywords: Family farming. Pluriativity. Rural Development.

\section{Resumen}

El objetivo de este trabajo es comprender la dinámica socio-económica que consiste en la explotación familiar en el municipio de Ribeirópolis/SE, tratando de identificar los factores que se pueden entender como actuando sobre la reproducción de unidades familiares Este municipio. Por lo tanto, de la revisión de la literatura y a través de discusiones en reuniones semanales en el grupo de investigación en medio Rural y la 
dinámica Regional (GDRR), además de recolección de datos secundarios y análisis, uno puede fundamentar teórica y empírico, la investigación en cuestión, además de realizar trabajo de campo donde 15 cuestionarios fueron aplicados y entrevistas semiestructuradas. Para señalar que rentas de actividades no agrícola, analizadas desde el trabajo de campo, son actividades de tipo albañil, pintor, limpiador, auxiliar de servicios generales y marchante.

Palabras-clave: Agricultura familiar. Pluriactividad. Desarrollo Rural.

Recebido em: 19/03/2018

\section{Introdução}

A partir de levantamento bibliográfico e análise reflexiva a respeito da pluriatividade têm-se subsídios para compreender as transformações recentes que passam a agricultura familiar. É nessa perspectiva que a pluriatividade será estudada como um fenômeno relacionado a disseminação da relação rural/urbano como forma de produzir atividades diversificadas e consequentemente funcionar como estratégia de fixação do pequeno produtor rural. Desde que se forneçam mecanismos para possibilitar que os agricultores familiares tenham na pluriatividade uma estratégia de fixação e diversificação das rendas das unidades familiares, caso contrário, à mesma poderá gerar a proletarização do meio rural na qual estiver inserida, como destaca Nascimento (2005), quando analisa o fenômeno na região Nordeste do Brasil.

Mapa 1- Localização do município de Ribeirópolis/SE.

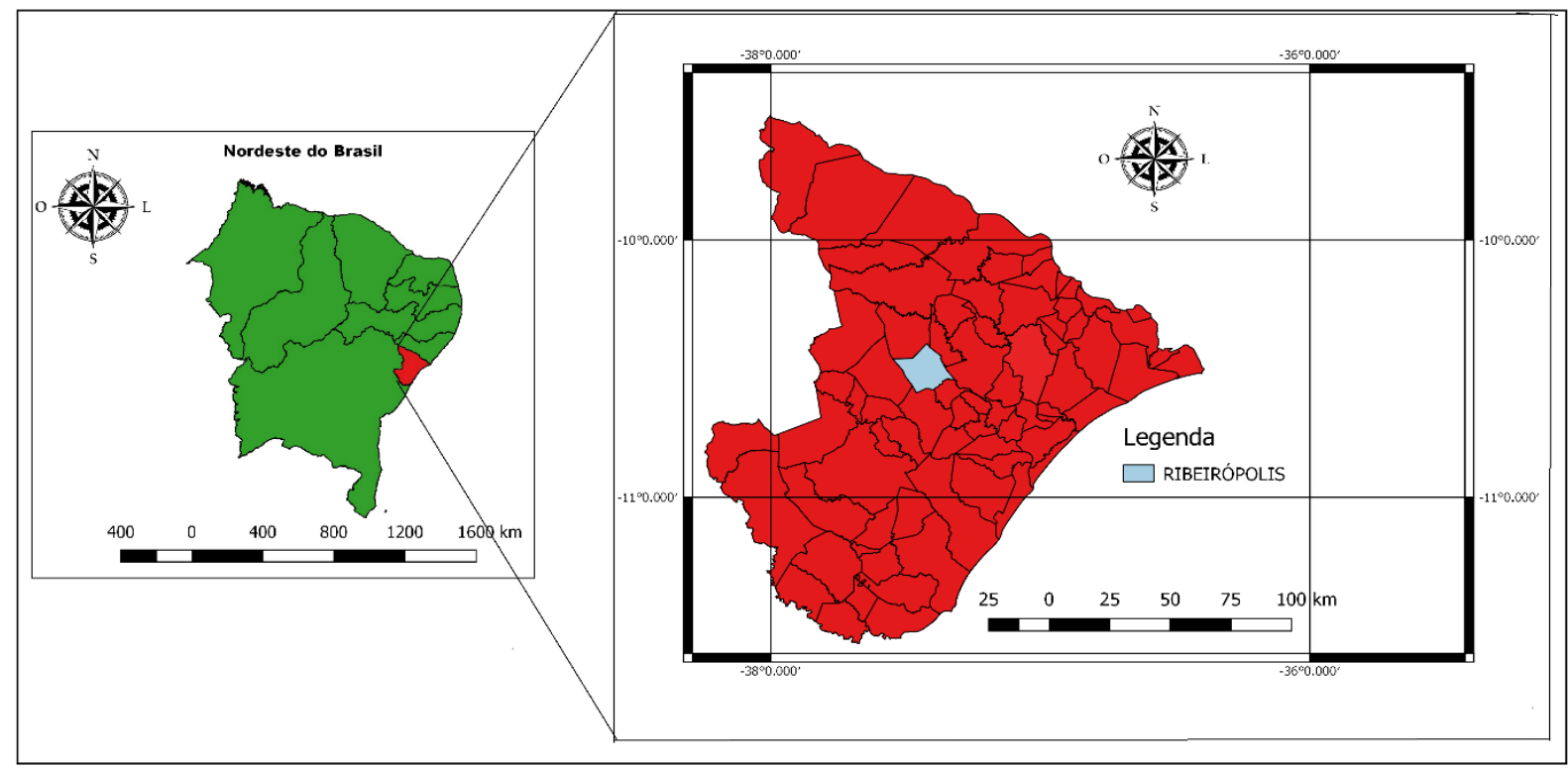

Fonte: Elaborado por Nascimento com base nos dados do Instituto Brasileiro de Geografia e Estatística (2018). 
O presente trabalho pretende fazer uma análise das condições da reprodução da agricultura familiar do município de Ribeirópolis/SE (mapa1), tomando-se a pluriatividade como estratégia de reprodução social e econômica das famílias rurais, reconhecendo a importância das políticas públicas para o fortalecimento da agricultura familiar. Ao mesmo tempo, o referido artigo busca compreender o processo de afirmação e/ou expropriação das famílias pluriativas diante do processo de modernização e dos avanços técnicos na agricultura sergipana.

É esperado reunir elementos que contribuam para a análise da realidade que envolve as possibilidades de compreensão da reprodução das unidades de agricultores familiares do município em questão. Nestes termos, o estudo pode proporcionar novos olhares sobre a realidade rural, assim como, estratégias de intervenção pública, que forneçam subsídios que contribuam para a inclusão dos pequenos produtores no sistema produtivo. Fundamentada nos resultados da pesquisa em questão, ao tempo que amplia o debate acadêmico e político a respeito do desenvolvimento rural.

Neste contexto, se destaca autores como Graziano da Silva (1993, 1996, 1997, 2000 e 2010) e Schneider (2003, 2006, 2007, 2010) importantes para fundamentar teoricamente e ampliar o olhar sobre o novo cenário da agricultura brasileira. Além desses autores também foram utilizados Nascimento (2005) e Mendes (2014), os quais fazem uma análise sobre as questões que envolvem a pluriatividade no caso do Nordeste e de Sergipe respectivamente.

Os autores citados acima são referência nas discussões sobre temas como, agricultura familiar, desenvolvimento rural e pluriatividade, no cenário da literatura nacional, além de Martins (2003) e Wanderley (2009) que também contribuem no estudo das novas questões que envolvem o meio rural brasileiro e as relações sociais que interferem nas atividades e na vida das famílias. Nesta perspectiva o município de Ribeirópolis/SE será utilizado como objeto de estudo para fins comparativos com a realidade da nova agricultura brasileira, principalmente, a partir da década de 1990, com o reconhecimento e ampliação do debate teórico sobre as novas atividades ocupacionais no ambiente rural.

Na pesquisa de campo realizou-se entrevista com o secretário municipal de agricultura do município de Ribeirópolis/SE, também foram trabalhadas quinze unidades familiares, sendo que estas responderam questionários semiestruturados referentes ao comportamento socioeconômico de cada, abordando atividades exercidas, área de concentração, escolaridade dos membros da unidade familiar e ocupação do chefe da família. Os dados coletados auxiliaram na fundamentação de algumas questões levantadas com o presente trabalho assim 
como, a coleta de dados secundários no Instituto Brasileiro de Geografia e Estatística (IBGE) e o Censo Agropecuário (1985 1995/6 e 2006).

\section{A diversidade do rural brasileiro}

No que se refere a importância da combinação das atividades agrícolas com as não agrícolas, fica clara a importância que estas vêm ganhando no meio rural brasileiro, onde a pluriatividade também pode ser enquadrada nesse poder de aumento da renda dos agricultores familiares, a medida em que ela é caracterizada pela combinação de atividades agrícolas com as não agrícolas, dessa forma diminuindo a dependência do agricultor em relação as sazonalidades a que as atividades agrícolas estão sujeitas. Então, autores como Graziano \& Del Grossi (2000), destacam a nova forma de dividir as atividades ocupacionais dos trabalhadores com domicílios agrícolas, como uma estratégia que acaba potencializando a renda das pequenas propriedades agrícolas.

Schneider (2000) ao analisar o caso da América Latina e do Brasil especificamente, ele chama a atenção para o fato de embora essa parte do mundo corresponda a países subdesenvolvidos, é evidente o crescimento das ocupações em atividades não agrícolas das pessoas com domicilio rural. Sendo assim cada vez menos se tem pessoas de áreas rurais ligadas apenas a atividades agrícolas, dessa forma ele destaca que.

No entanto, essa redução da população ocupada em atividades agrícolas não significa que haja uma retomada do êxodo rural iniciado na década de 1960. No período recente, especialmente a partir dos anos oitenta, a queda do emprego agrícola tem sido compensada parcialmente pelo crescimento da população rural ocupada em atividades não agrícolas. Isso é o que mostra o trabalho de Klein (1992), que além de reconhecer que a migração rural urbana influenciou a queda da PEA agrícola, indica que essa redução também pode ser atribuída às mudanças recentes das novas formas de ocupação do meio rural. (SCHNEIDER, 2000, p, 11).

A industrialização fez surgir um novo ator no meio rural, que incorpora inúmeras atividades ocupacionais as quais permitem classificá-lo como agricultor em tempo parcial, e busca cada vez mais está inserido no sistema, o qual, sobrevive sem deixar de desenvolver suas atividades agrícolas em alguns dias da semana.

No que se refere a essa combinação entre atividades agrícolas e não agrícolas, por parte dos agricultores familiares, fez surgir o fenômeno da pluriatividade. Assim, para Schneider (2007), é um fenômeno que opera no seio da unidade familiar e tem como uma de suas principais potencialidades, a de elevar a renda familiar e diversificar os lucros das unidades familiares. Sobre essa temática Nascimento (2005) discorda de Schneider (2007), 
onde o primeiro atribui para a adesão a pluriatividade algo que vai além da decisão da unidade familiar.

No que se refere à pluriatividade Nascimento (2005) destaca que se torna importante considerar mais fatores que determinam a disseminação da pluriatividade além das decisões da família, pois a partir de uma análise do caso na região Nordeste fica evidente que as razões que estão influenciando o seu maior crescimento em relação a região Sul, são razões que advêm muito de uma necessidade de que uma opção das famílias nordestinas, e é preciso se analisar as razões que estão levando ao declínio da pluriatividade no sul do país. Já Lopes (2009), quando aborda a questão da pluriatividade no estado de Sergipe, ele observa que cada vez mais as atividades não agrícolas veem se disseminando no meio rural brasileiro. E Sergipe não foge à regra, os domicílios pluriativos também apresentam elevação na renda, mas como pode ser evidenciado na região Nordeste, as ocupações não agrícolas em Sergipe também tendem a se concentrar em atividades que exigem pouca qualificação. É o caso de profissões como pedreiro, pintor, domestica além de pessoas com domicilio rural empregadas na indústria têxtil ou de calçados.

Nascimento (2005) destaca a importância de se repensar as políticas de fortalecimento rural no Brasil, visto que a maioria dos recursos são destinados para as maiores propriedades, e o local onde se tem o maior desenvolvimento, no que se refere a produção de empregos são as pequenas propriedades, onde se desenvolvem atividades agrícolas e não agrícolas, sendo que essas propriedades em muitos casos localizam-se em áreas de transição rural urbano, que muitas vezes não se enquadram no perfil, do Programa Nacional de Fortalecimento da Agricultura Familiar (PRONAF) o qual acaba deixando os estabelecimentos classificados como periféricos fora do padrão dos beneficiários. Nascimento (2005) destaca algumas falhas nas políticas públicas destinadas ao desenvolvimento rural, pois não conseguem atingir de forma igualitária todos os seguimentos da agricultura familiar brasileira, como destaca a seguir:

Nesse sentido, pode-se afirmar que os segmentos mais favorecidos pela política do Estado de modernização da agricultura foram aqueles que representavam a menor fração do conjunto dos produtores rurais do país agricultores patronais e uma pequena parcela da agricultura familiar associada às agroindústrias. Esse favorecimento decorria de falhas no mecanismo de distribuição do crédito rural levando-o a se concentrar nas mãos daqueles grupos de produtores com maior acesso a informações e maior influência política, de modo que o crédito se concentrou nas mãos de poucos agricultores e foi destinado a poucas culturas (...). (NASCIMENTO, 2005, p.15). 
Tomando como referência Schneider (2007) é preciso entender que a pluriatividade irá servir como uma estratégia de reprodução da agricultura familiar em domicílios pobres, assim para que ocorra o sucesso na aplicação de políticas públicas voltadas para o incentivo da pluriatividade, é preciso ocorrer o conhecimento sobre o tema por parte dos gestores, capacitação e um olhar especial para os jovens, pelo fato de serem eles que representam o maior fluxo de migração campo cidade.

Nascimento (2005) considera que a pluriatividade se desenvolve mais em regiões consideradas pobres como é o caso do nordeste, pois as condições de baixo desenvolvimento tecnológico da agricultura favorecem a pluriatividade, onde segundo o autor regiões com maior grau de modernização tecnológica favorecem menos a pluriatividade. Já que em áreas onde as atividades agrícolas se encontram em declínio, a combinação das mesmas com as atividades não agrícolas surgem como uma estratégia das famílias pobres para uma diversificação das rendas e aumento da renda familiar, dessa forma com o declínio das atividades agrícolas e cada vez menos incentivos do governo em setores que não apresentam desenvolvimento tecnológico, a pluriatividade aparece com uma alternativa de resistência das famílias com domicílios rurais para a permanência no campo. Nascimento (2005) ainda destaca que somente a adesão a pluriatividade por parte da família, não é capaz de modificar a realidade social dela, já que será necessária uma série de fatores como ele destaca a seguir, para evitar que essa família entre em um processo de proletarização, ou abandone as atividades agrícolas.

No que se refere a pluriatividade torna-se importante destacar Nascimento (2005), pois é preciso os fatores que determinam o desenvolvimento da pluriatividade, além das decisões da família. Assim a partir de uma análise do caso na região Nordeste, fica evidente que as razões que estão influenciando o seu maior desenvolvimento em relação a região Sul, são razoes que advêm muito mais de uma necessidade, de que uma opção das famílias nordestinas, e é preciso se analisar os determinantes que estão levando ao declínio da pluriatividade no Sul do país.

Com base nos argumentos relatados acima, cabe destacar que a pluriatividade se desenvolve mais em regiões consideradas, pobres como é o caso do Nordeste, pois as condições de baixo desenvolvimento tecnológico da agricultura favorecem a pluriatividade, e para Nascimento (2005) regiões com maior grau de modernização tecnológica favorecem menos a pluriatividade. Em áreas onde as atividades agrícolas se encontram em declínio, a combinação das mesmas com as atividades não agrícolas surge como uma estratégia das famílias pobres para uma diversificação e aumento da renda familiar, dessa forma com o 
declínio das atividades agrícolas e cada vez menos incentivos do governo em setores que não apresentam desenvolvimento tecnológico, a pluriatividade aparece com uma alternativa de resistência das famílias com domicílios rurais para a permanência no campo. Para o autor quando se é comparado o crescimento da pluriatividade entre as regiões nordeste e sul fica evidente, o maior crescimento na região Nordeste. Pois a região Sul apresenta melhor índice de desenvolvimento tecnológico do setor agrícola, e a necessidade pela procura por outras atividades não se torna tão essencial quanto na região nordeste.

\section{Desafios e perspectivas para a agricultura familiar brasileira}

É consenso entre os estudiosos, que o meio rural brasileiro vem passando por transformações, tais como a disseminação da tecnologia e a incorporação de novos mercados de trabalho e comercialização, fazendo-se necessário ampliar o olhar e o debate em torno das questões que envolvem o fortalecimento da agricultura familiar, principalmente após a segunda parte do século XX. Sendo assim, a agricultura familiar brasileira apresenta heterogeneidade, principalmente, devido à diversidade presente não apenas no meio rural, mas também, nas áreas urbanas, as quais acabam influenciando de forma direta ou indireta as atividades e a forma de se organizar das unidades familiares rurais. Consequentemente, as discussões sobre o fortalecimento da agricultura familiar envolvem diversas questões e consequências em torno da pobreza rural, da geração de renda e da (i) racionalidade econômica e/ou imperfeição dos mercados, além da inserção tecnológica das unidades familiares, assim como a relação rural/urbano para compreensão das atividades agrícolas e/ou não agrícolas presentes no novo rural brasileiro.

Fajardo (2008) atribui o desenvolvimento da agricultura algo que ele denomina como a formação do complexo agroindustrial (CAI), a partir disso, surge a integração dos setores da agricultura com a indústria, além da expansão da política de crédito rural, algo importantíssimo no processo de desenvolvimento da agricultura, o qual foi segundo Fajardo (2008) decisivo no processo de desenvolvimento do CAI no estado do Paraná.

Nesse estado, como em outros, a política de crédito rural foi decisiva para a modernização significando a maior parte no volume de vendas de tratores e do consumo de fertilizantes. Sendo o Paraná, sobretudo nos anos 1970, o estado onde houve a maior expansão das áreas de soja e trigo, o consumo de insumos modernos para essas lavouras foi enorme graças aos créditos oferecidos e destinados especialmente às mesmas culturas. (FAJARDO, 2008, p.39).

Sendo assim, é possível observar que ao mesmo tempo em que a agricultura brasileira apresenta locais em que se tem uma marcante integração da agricultura com a indústria, ainda 
existem áreas do país que precisam duelar contra elementos os quais acabam barrando o desenvolvimento deste setor. Martins (2003) destaca a manipulação ideológica sobre os assentados, os quais se sentem empregados das instituições intermediadoras da reforma agrária e acabam ficando reféns de funcionários do Estado que visam no movimento o alcance de algumas metas pessoais e também agem de forma camuflada no movimento.

Graziano da Silva (1997) caracteriza a agricultura familiar brasileira como algo que ele classifica sendo "o novo rural brasileiro", ao tempo em que o mesmo não irá se destinar apenas para a produção agrícola, mas a atender setores como o turismo, lazer, pesca esportiva e outros, dessa maneira, ele resume trazendo as potencialidades desse novo rural que além de dinamizar a economia traz benefícios na área ambiental e social.

Ainda nesta direção Graziano da Silva e Del Grossi (2000), destacam a nova forma de dividir as atividades ocupacionais dos trabalhadores com domicílios agrícolas, como estratégia que acaba potencializando as rendas das pequenas propriedades agrícolas, onde segundo eles esse incremento de atividades não agrícolas pode ser associado à queda da renda oriunda das atividades agrícolas.

Nesses termos os desafios da agricultura familiar, principalmente no caso do Nordeste, vão além de problemas como a seca, onde a diversificação do trabalho surgiu como uma alternativa das famílias rurais. Consequentemente a pluriatividade pode representar uma das formas para promover a sustentação das famílias rurais, com a combinação de duas ou mais atividades, sendo que uma delas seja a agricultura. Dessa maneira, a pluriatividade poderá ser uma saída para a família residente em áreas rurais não apenas para a ampliação da renda, como também, para algo que é destacado em Mendes (2014), no qual ele aponta que a importância da pluriatividade para a unidade familiar é determinada por diferentes variáveis, “O princípio básico para demonstrar o significado da pluriatividade está relacionado à conquista da confiança, autoestima e da dignidade dos agricultores familiares, (re) conquistada a partir de atividades que promovem a inserção profissional e social dos agricultores familiares" (MENDES, 2014, p.193). Com isso, as famílias rurais recorrem às atividades não agrícolas, não só como uma alternativa para continuar no meio rural, como também no caso das famílias pobres serviria como uma ponte para a passagem de uma atividade a outra, e até a saída da situação de pobreza.

Mas torna-se necessário destacar algumas tendências presentes na região Nordeste do Brasil que afetam diretamente o rumo destas atividades não agrícolas, sendo que, a partir dos dados do Instituto Brasileiro de Geografia de 1990-2010, verifica-se os baixos índices de escolaridade presentes na região, refletem na concentração de atividades remuneradas com 
salários inferiores a 3 salários mínimos. Então, serão destacadas no próximo ponto algumas questões, as quais envolvem as potencialidades da pluriatividade, mas chamando a atenção para alguns aspectos que a caracteriza no município de Ribeirópolis/SE, aonde se pode destacar a dificuldade de se chegar a uma determinada característica que determine as condições favoráveis para o desenvolvimento da pluriatividade. Portanto, são variadas as áreas aonde se dão o desenvolvimento das famílias pluriativas, em um país que tem cada área com sua característica específica, assim torna-se importante discutir o que autores como, Schneider (2000), Mendes (2014) e Nascimento (2005) pensam sobre o tema, os quais podem ser considerados como referência no estudo do fenômeno da Pluriatividade.

\section{A relação rural/urbano em Ribeirópolis/SE}

De acordo com os dados do IBGE (censo 2010), o município de Ribeirópolis/SE possui uma população de 17.173(hab.), ocupando uma área total de 259,022 $\left(\mathrm{km}^{2}\right)$, correspondendo a uma densidade demográfica de $66,42\left(\mathrm{hab} . / \mathrm{km}^{2}\right)$, sendo que a estimativa populacional de 2016 corresponde a 18.503 (hab.). As principais atividades desenvolvidas no meio rural estão ligadas a agropecuária, (com destaque para a criação de bovinos, suínos e caprinos), além da produção de leite, das principais atividades ligadas à lavoura, cabe destacar a produção de banana, laranja, mandioca, milho e o feijão.

Tabela 1- População Total, por Gênero, Rural/Urbana em Ribeirópolis/SE de 2000 a 2010

\begin{tabular}{l|l|l|l|l|l|l}
\hline População & $\begin{array}{l}\text { População } \\
(1991)\end{array}$ & $\begin{array}{l}\% \text { do } \\
\text { Total } \\
(1991)\end{array}$ & $\begin{array}{l}\text { População } \\
(2000)\end{array}$ & $\begin{array}{l}\text { \% do Total } \\
(2000)\end{array}$ & $\begin{array}{l}\text { População } \\
(2010)\end{array}$ & $\begin{array}{l}\text { \% do Total } \\
(2010)\end{array}$ \\
\hline População total & 14.032 & 100,00 & 15.439 & 100,00 & 17.173 & 100,00 \\
\hline $\begin{array}{l}\text { População residente } \\
\text { masculina }\end{array}$ & 6.851 & 48,82 & 7.637 & 49,47 & 8.492 & 49,45 \\
\hline $\begin{array}{l}\text { População residente } \\
\text { feminina }\end{array}$ & 7.181 & 51,18 & 7.802 & 50,53 & 8.681 & 50,55 \\
\hline População urbana & 7.875 & 56,12 & 10.095 & 65,39 & 11.928 & 69,46 \\
\hline População rural & 6.157 & 43,88 & 5.344 & 34,61 & 5.245 & 30,54 \\
\hline
\end{tabular}

Fonte: Instituto Brasileiro de Geografia e Estatística, Agosto de 2017.

A tabela 1, representa uma síntese referente a evolução da população total (rural e urbana) e por gênero no município de Ribeirópolis/SE, onde observa-se o fato de que a taxa de crescimento da população feminina ter se mantido positiva em todos os extratos da representação, assim, é possível afirmar que a mulher assume posições jamais vivenciadas na sociedade liderada pelo sistema capitalista, através de práticas e representações profissionais distintas, dessa maneira é possível destacar a importância que a mão de obra feminina ganhou nas últimas décadas para o fortalecimento da agricultura familiar e com base em Mendes 
(2014), ressalta-se o fortalecimento da autoestima feminina e das relações de poder dentro da unidade familiar, tendo em vista que a mulher vem ganhando cada vez mais destaque dentro da sociedade.

Sen (2010) ressalta que um dos princípios básicos do desenvolvimento como liberdade, está atrelado a liberdade substantiva das pessoas em levar a vida que elas têm razão em valorizar, sendo este o alicerce da "capacidade humana". Nessa perspectiva, a educação é o principal caminho para a expansão das capacidades humanas e a busca pela mudança social, (deixando o enfoque econômico em segundo plano), consequentemente destaca-se que a expansão das capacidades humanas deve levar em consideração, o bem-estar e a liberdade das pessoas, influenciando o processo de mudança social e inevitavelmente ocorrerá a produção econômica. Portanto o pensamento de Sen (2010) deve ser compreendido como uma referência no tocante as discussões sobre estarégias capazes de entender os caminhos para melhorar a realidade social dos agricultores inseridos em Ribeirópolis em Sergipe e no Nordeste, como é possível observar a partir dos dados do gráfico 1.

Gráfico 1- Evolução do Índice de desenvolvimento Humano médio no Brasil, Nordeste, Sul em Sergipe e em Ribeirópolis/SE 1991-2010.

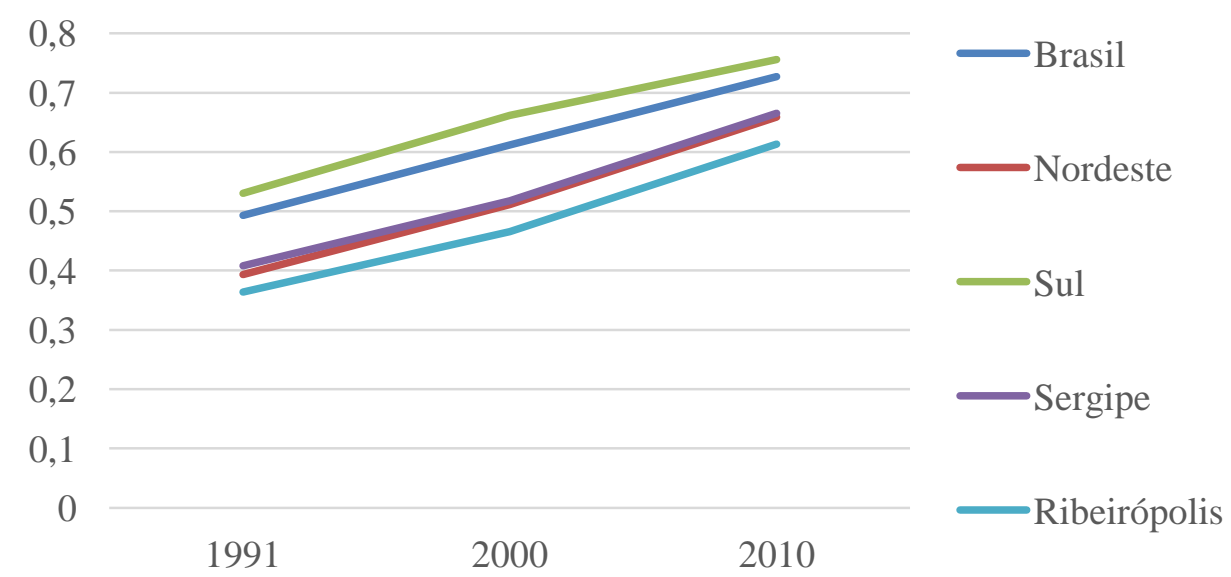

Fonte: Organizado por João Ernandes B. Nascimento, (setembro, 2017) com base nos dados do Atlas do Desenvolvimento Humano no Brasil (2013)

Com base nos dados do gráfico 2 é possível observar que, dentre os domicílios pesquisados, os domiciliados agrícolas tendem a buscar ocupações em outros domicílios ou até mesmo em atividades não agrícolas para garantir a manutenção da família, fator que é considerado determinante ao desencadeamento da pluriatividade por autores como Schneider (2007) e Mendes (2014). Dessa maneira, a diversificação não apenas das atividades como também das rendas acaba, refletindo diretamente no padrão e na qualidade de vida dos agricultores familiares. Destaca-se que os agricultores que se enquadraram neste perfil, 
apresentavam melhores condições de vida, pois, ficam menos vulneráveis aos períodos de seca, e, dependem menos da sazonalidade das atividades agrícolas para gerar os rendimentos da unidade familiar.

Gráfico 2- Características dos trabalhadores dos domicílios agrícolas de Ribeirópolis/SE

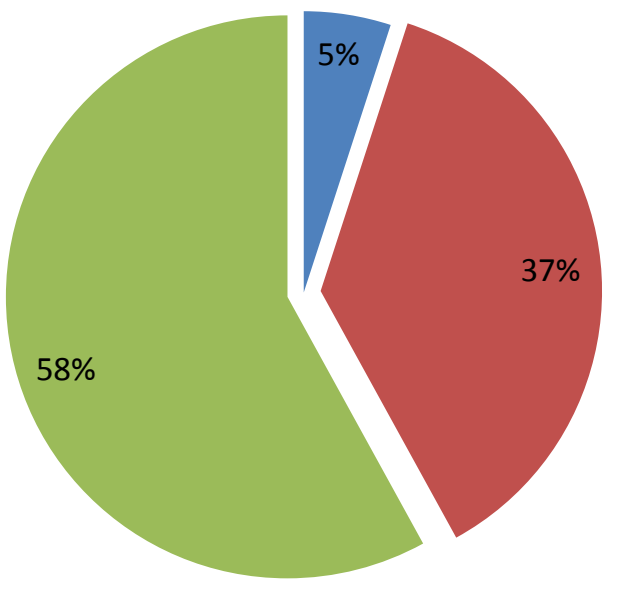

- Ocupados somente no próprio domicílio

- Ocupados em atividades agrícolas de outros domicílios

Conbinam atividades agrícolas e não agrícolas

Fonte: Organizado por João Ernandes B. Nascimento com dados do trabalho de campo (2015)

O gráfico 3 caracteriza a concentração das principais fontes de renda dos domiciliados agrícolas pesquisados. Percebe-se a concentração em atividades não agrícolas, sendo que essa concentração pode ser associada ao que Graziano (1997) associam ao declínio das atividades agrícolas, o que se torna um dos fatores que irão propiciar o desencadeamento das atividades não agrícolas no meio rural. Consequentemente a combinação com as atividades agrícolas, por parte do agricultor familiar, ganha destaque na literatura nacional a partir da década de 1990, compreendendo-a como uma das novas formas de permanecerem no meio rural.

Gráfico 3- Principais fontes de renda dos domicilios rurais de Ribeirópolis/SE

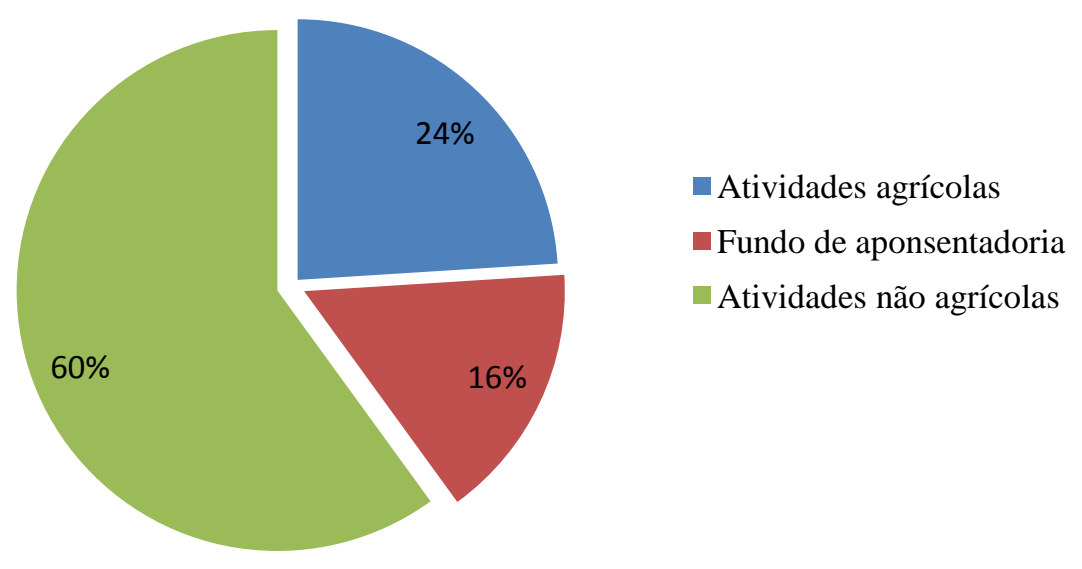

Fonte: Organizado por João Ernandes B. Nascimento com dados do trabalho de campo (2015) 
Pode-se destacar ainda, algo que é apresentado no estudo feito por Nascimento (2005), onde o autor destaca que as atividades não agrícolas na região Nordeste tendem a se concentrarem em setores que atribuem baixa remuneração. Isso foi constatado em diálogos com alguns agricultores que relatam que já tentaram abandonar o trabalho com as atividades agrícolas, e dessa maneira, tentaram trabalhar em áreas urbanas, mas devido ao baixo índice de escolaridade do agricultor o emprego que era encontrado acabava sendo ainda mais cansativo e mal remunerado do que o encontrado na agricultura, devido ao baixo grau de escolaridade do indivíduo.

Para Leite et. All. (2009) o rural não se resume apenas ao agrícola, sendo também um setor econômico, consequentemente, torna-se relevante a participação das famílias rurais nas discussões e administrações públicas. Um elemento associado a isso consiste na desarticulação existente entre o conselho municipail de desenvolvimenti rural, pois verifica-se a incapacidade de articulação do colegiado territorial, a medida em que, os agricultores dificilmente dialogam com as entidades e não evidencia-se conexão entre os agentes de desenvolvimento rural.

Gráfico 4 - Percentual dos domicílios rurais com rendimento inferior a três salários mínimos no Brasil, no Nordeste em Sergipe e em Ribeirópolis/se 2000-2010

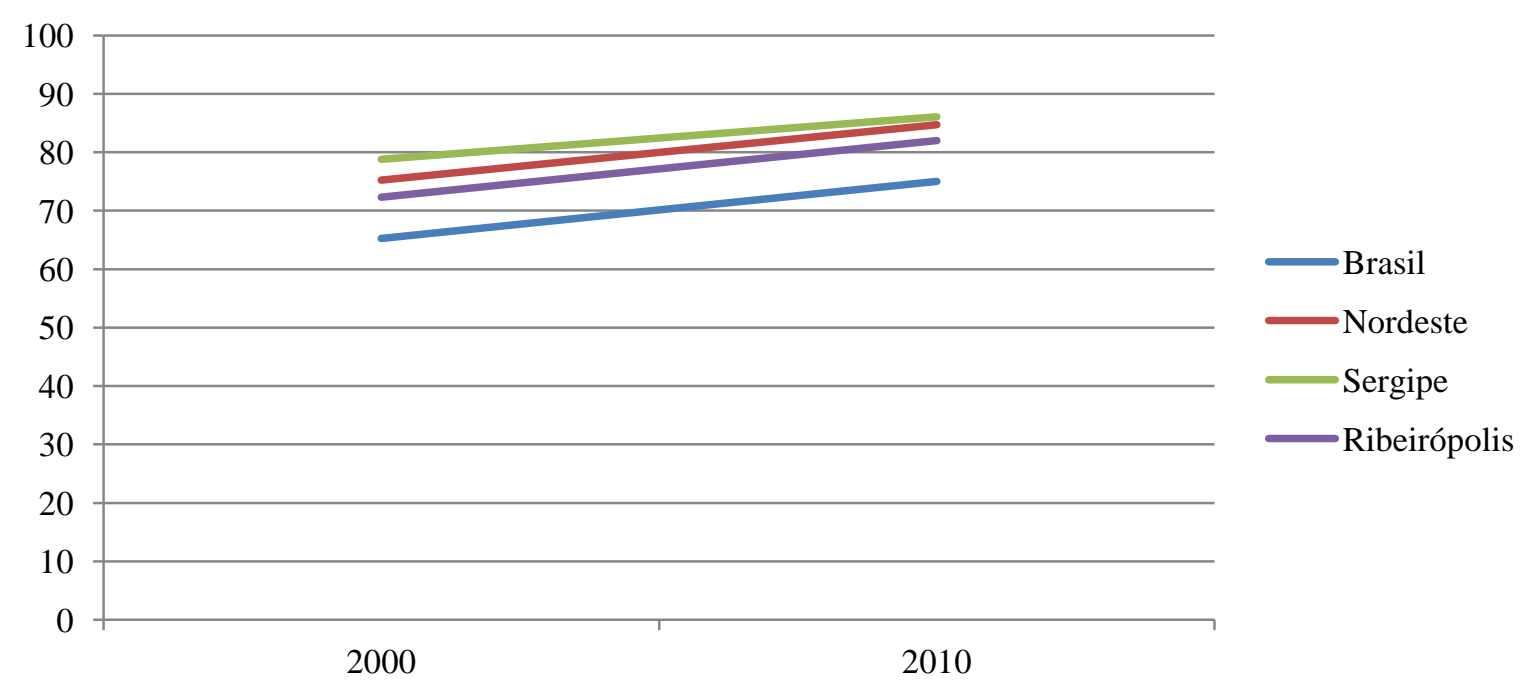

Fonte: Instituto Brasileiro de Geografia e Estatística, (setembro, 2017)

No gráfico 4, percebe se que cada vez mais se tem domicílios rurais no Nordeste, com rendimentos inferiores a três salários mínimos, apontando para a necessidade de se repensar as políticas públicas para o meio rural, assim como, ações capazes de gerar renda para esses agricultores familiares, ao tempo que, o baixo nível de instrução presente nas unidades familiares, tem como consequência a concentração cada vez maior de domicílios envolvidos em atividades mal remuneradas. Mesmo assim, a alternativa em recorrer a essas atividades 
que atribuem baixa remuneração, é apontada por Nascimento (2005), como uma alternativa para os agricultores familiares tentarem permanecer no meio rural, pois, o baixo índice de escolaridade desses agricultores, como é apontando por Cardoso (2013), acaba tendo reflexo no tipo e rendimento das atividades remuneradas exercidas fora do domicílio familiar. Portanto, esses fatores servem como base para ressaltar o pensamento de Mendes (2014), pois, o autor chama a atenção, para o fato de torna-se importante a discussão e aplicação de políticas públicas capazes de promover o fortalecimento da agricultura familiar no Nordeste, observando que caso isso não ocorra esses problemas tenderam a agravarem-se, poderão aumentar os problemas existentes nas áreas urbanas.

A partir do quadro 1, é possível refletir sobre aonde estão concentradas as ocupações dos chefes de família com domicílios agrícolas, das unidades familiares analisadas. Cabe destacar que as atividades agrícolas concentram-se em serviços como vaqueiro, morador, roceiro, entre outros. Ainda com base no quadro é possível que se identifique a presença marcante das atividades não agrícolas no meio rural do município. Mas no caso dos domicílios que apresentam maior dependência das atividades agrícolas, foi possível verificar a queda do padrão de vida dos agricultores, se comparados com os agricultores mais dinâmicos e pluriativos, sendo que os entrevistados apresentavam maior dependência em relação às atividades agrícolas, além do que pode ser caracterizado como um modo de vida tradicional, na medida em que a maioria desses agricultores dedica-se a "vender o dia", trabalhando em propriedades de terceiros.

Quadro 1- Principal do chefe das famílias nas unidades familiares de Ribeirópolis/SE (em \%).

\begin{tabular}{|c|c|}
\hline Ocupação & Total \\
\hline Trabalhador rural & $40 \%$ \\
\hline Marchante de boi & $30 \%$ \\
\hline Autônomo em comércio não específico & $23 \%$ \\
\hline Sem ocupação/aposentado & $10 \%$ \\
\hline Total & $100 \%$ \\
\hline
\end{tabular}

Fonte: Organizado por João Ernandes B. Nascimento com dados do trabalho de campo (2015)

O gráfico 05 representa os baixos índices de escolaridades do município de Ribeirópolis/SE, os quais podem ter como uma de suas principais consequências às atividades de baixa remuneração das áreas em questão, o que acaba refletindo nos tipos de atividades não agrícolas realizadas por estes agricultores, e consequentemente, concentrando estas atividades em setores como ajudante de pedreiro, carroceiro e faxineira. Com isso, é possível destacar a importância da combinação de atividades agrícolas e não agrícolas nestas unidades familiares, mas é importante ressaltar que as atividades não agrícolas tendem a se concentrar, 
cada vez mais, em setores que atribuem baixa remuneração a estes agricultores e exigem pouca escolaridade dos mesmos, como é o caso dos agricultores representados no quadro 2 .

Gráfico 5 - Escolaridade da populção com 25 anos ou mais em Ribeirópolis/SE (1991-2010).

60

40

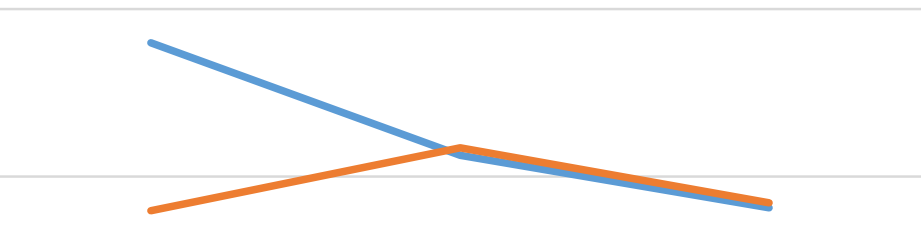

20

0

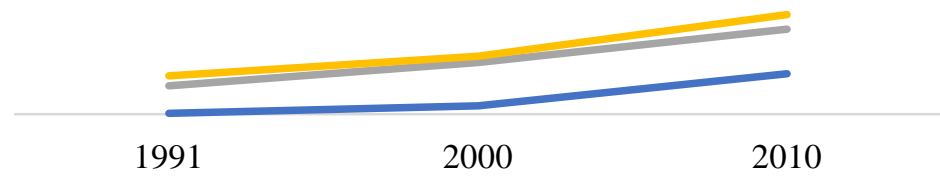

- Fundamental incompleto e/ou analfabeto

Fundamental incompleto e/ou alfabetizado

Fundamental completo e/ou médio incompleto

- Médio completo e/ou superior incompleto

- Superior completo

Fonte: Instituto Brasileiro de Geografia e Estatística, (setembro, 2017)

Cabe destacar, a importância de que ao analisar e classificar a relação rural/urbana na atualidade deve-se levar em consideração um fator citado em Wanderley (1997), pois, a autora chama a atenção para maneira de se determinar o que é rural e urbano no Brasil. Por isso, um agricultor que resida na cidade é considerado urbano, mesmo que todas as suas atividades diárias sejam desempenhadas no meio rural. Assim como o morador do meio rural é considerado agricultor, mesmo que suas rendas sejam também ou somente oriundas de atividades exercidas nas zonas consideradas urbanas, nessa perspectiva, para que seja possível a compreensão mais próxima da realidade social, tornam-se necessários enxergar o rural e o urbano como um espaço socialmente construído e intersetorial.

Quadro 2- Atividade ou fonte de renda correspondente a maior parcela da renda da família em Ribeirópolis/SE (em \%)

\begin{tabular}{|c|c|}
\hline Atividade & Total \\
\hline Aposentadoria & $8 \%$ \\
\hline Atividades agrícolas & $16 \%$ \\
\hline $\begin{array}{c}\text { No comercio ou por conta própria/marchante, } \\
\text { pedreiro. }\end{array}$ & $24 \%$ \\
\hline Total & $52 \%$ \\
\hline
\end{tabular}

Fonte: Organizado por João Ernandes B. Nascimento com dados do trabalho de campo (2015)

Comparando os quadros 2 e 3, observa-se algo que é destacado em Nascimento (2005), sendo que as atividades não agrícolas desempenhadas pelos agricultores familiares da região Nordeste tendem a concentrarem-se em áreas que exigem baixo grau de instrução. No tocante ao município de Ribeirópolis, as características são semelhantes, devido aos autos 
índices de analfabetismo no meio rural e ao baixo conhecimento cientifico, e, assim, as atividades não agrícolas tendem a se concentrar em serviços de pedreiro, marchante de boi, cabendo destacar ainda atividades desempenhadas, na indústria do calçado e da linha.

Vale ressaltar ainda, que o número de trabalhadores na indústria do calçado ainda poderia ser maior, pois, recentemente (pouco antes da realização da pesquisa de campo) a fábrica da Azaleia da cidade de Ribeirópolis havia sido fechada e estes trabalhadores encontravam-se (no período da entrevista) desempregados ou trabalhando em outra empresa de calçados do município de Nossa Senhora Aparecida.

Quadro 3- Grau de escolaridade dos domiciliados agrícolas de Ribeirópolis/SE (em \%).

\begin{tabular}{|c|c|}
\hline Escolaridade & Total \\
\hline Analfabeto & $51 \%$ \\
\hline Fundamental incompleto & $35 \%$ \\
\hline Fundamental completo & $4 \%$ \\
\hline Médio incompleto & $7 \%$ \\
\hline Nível superior completo & $3 \%$ \\
\hline Total & $100 \%$ \\
\hline
\end{tabular}

Fonte: Organizado por João Ernandes B. Nascimento com dados do trabalho de campo (2015)

Nesses termos, quando se analisa o desencadeamento da pluriatividade nesta porção da região Nordeste, é possível confrontar dados apresentados por autores como Schneider (2000), que atribuem potencialidades a pluriatividade, apenas a partir da realidade evidenciada na região Sul do país, o qual apresenta características bastante particulares de organização econômica, social e cultural se comparada com a maior parte da região Nordeste. Dessa forma, o desencadeamento da pluriatividade vai muito além de uma decisão do núcleo familiar, aonde será necessário que se leve em consideração todo um contexto espacial que envolve a área onde a mesma encontra-se inserida. Fatores como o social, cultural, educacional e econômico, são determinantes para o desenvolvimento de forma positiva ou negativa desse fenômeno.

Foto 1- Feirinha da agricultura familiar no município de Ribeirópolis/SE.

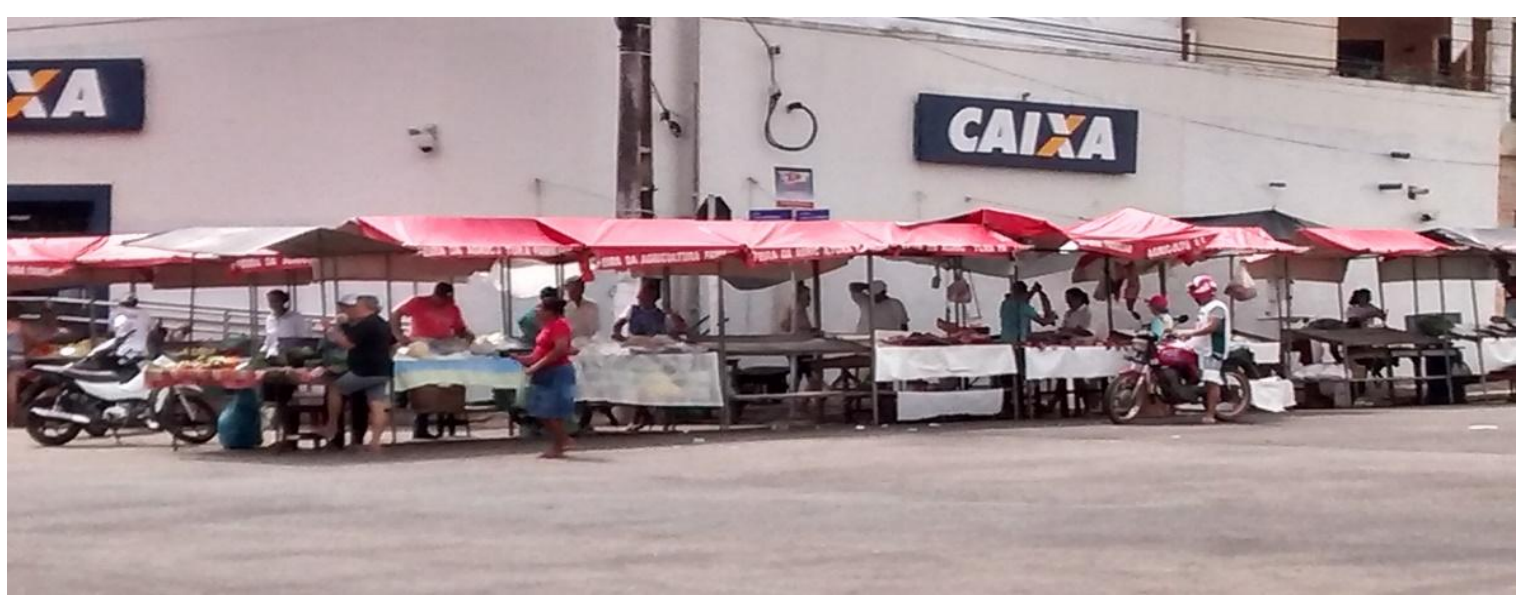

Fonte: Foto de João Ernandes B. Nascimento; rabalho de campo, (dezembro, 2017) 
A feirinha da agricultura familiar organizada pelos agricultores familiares do município de Ribeirópolis/SE, (foto 1) representa uma oportunidade para a inserção dos produtos agrícolas no mercado local da cidade, é possível chamar a atenção para a assistência ineficiente prestada pelos órgãos públicos, pois segundo os agricultores, o único apoio recebido, refere-se a organização das bancas para a comercialização na feira. O secretário municipal de agricultura reafirma a dificuldade a auxiliar a no desenvolvimento da agricultura familiar do município, diante da escassez de recursos, a prefeitura consegue apenas fornecer serviços básicos como a terraplanagem das estradas vicinais e limpeza das fontes que armazenam água.

Painel 1- Algumas ações do Estado no Território do Sertão Ocidental de Sergipe.

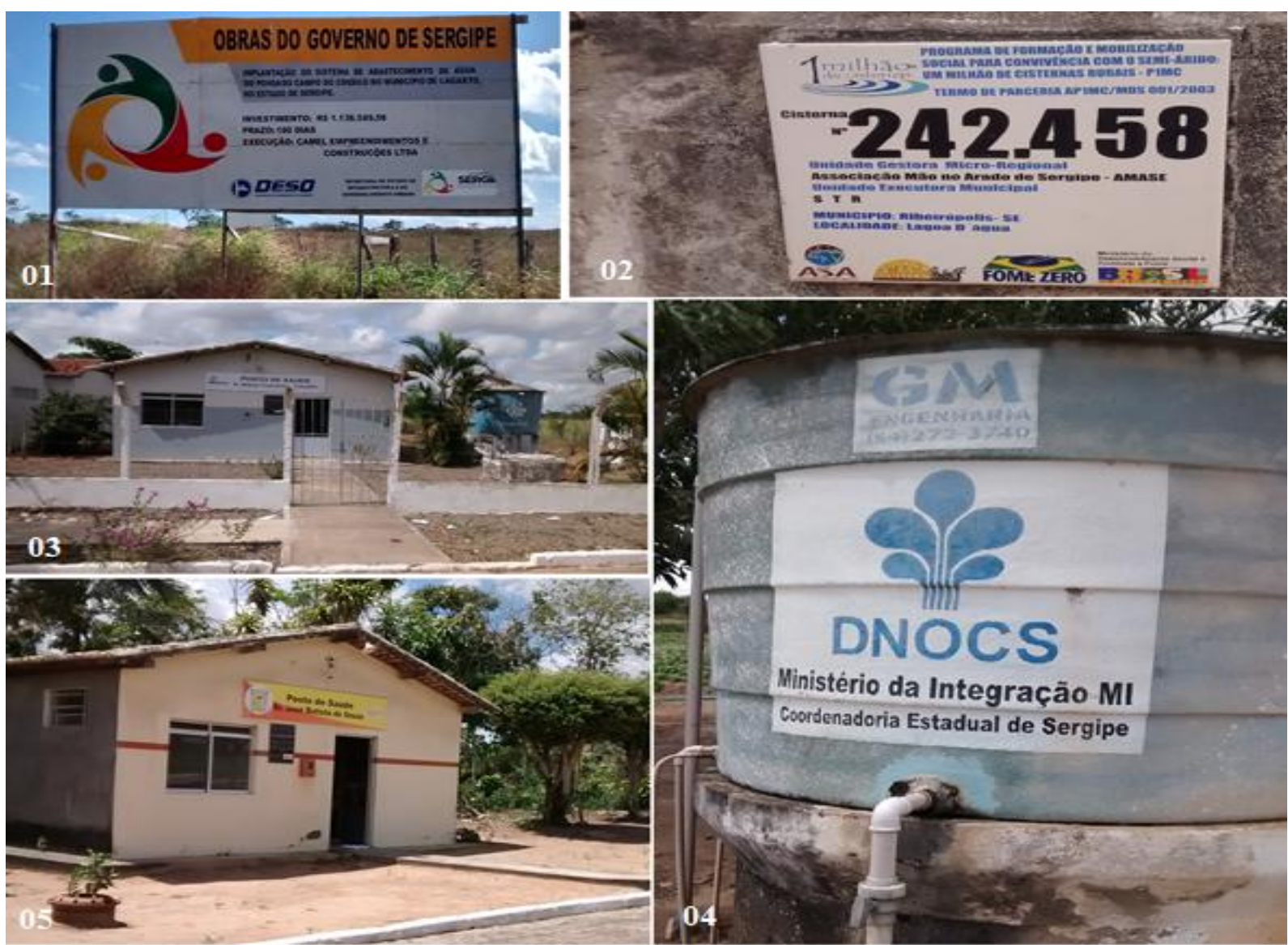

Fonte: Foto de João Ernandes B. Nascimento; rabalho de campo, (dezembro, 2017)

O Painel 1 representa algumas imagens de ações do Estado evidenciadas no município de Ribeirópolis/SE, onde na imagem 01 verifica-se a construção do sistema de abastecimento, viabilizado pelo Governo do estado de Sergipe, na imagem 02 observa-se uma das cisternas destinadas ao território, através do programa 1 milhão de Cisternas do Governo Federal, assim como a construção de um reservatório de água, adquirido com recursos do Ministério da 
Integração e em parceria com o Governo do estado de Sergipe, e por fim, as imagens 03 e 05, representam a construção de alguns postos de saúde no território.

Nesses termos, é possível afirmar a relevância de ações do Estado para alavancar o desenvolvimento rural, em consequência disso, é relevante ampliar as ações com foco na saúde, educação e combate à falta de dificuldade em armazenar água, caso contrário as ações terão reflexos pontuais e entrarão sucateamento dos bens públicos, pois as políticas públicas são capazes de conduzir o desenvolvimento rural, principalmente, em áreas mais carentes como é o caso do município em questão.

\section{Considerações finais}

O presente trabalho buscou fazer uma análise das condições da reprodução da agricultura familiar do município de Ribeirópolis/SE, tomando-se a pluriatividade como estratégia de reprodução social e econômica das famílias rurais. Ao mesmo tempo, o referido artigo busca compreender o processo de afirmação e/ou expropriação das famílias pluriativas diante do processo de modernização e dos avanços técnicos na agricultura sergipana.

É nessa perspectiva que se compreende a pluriatividade como potencialidade a ser desenvolvida no espaço rural como forma de produzir atividades diversificadas e consequentemente funcionar como estratégia de fixação do agricultor familiar em sua atividade agrícola e/ou não agrícolas. Desde que se forneçam mecanismos para possibilitar que os agricultores familiares tenham na pluriatividade uma estratégia de fixação e diversificação das rendas das unidades familiares, caso contrário à mesma poderá gerar a proletarização do meio rural na qual estiver inserida.

Nesses termos, torna-se interessante conhecer a dinâmica da agricultura familiar na área em questão e, assim, discutir elementos que propiciem ao Estado elaborar políticas públicas voltadas para atender as reais necessidades de cada localidade, que diante do processo de modernização da agricultura contemporâneo, é evidente que cada área do país irá se comportar de acordo com as possibilidades do contexto espacial no qual se encontram inseridas, por isso as políticas públicas precisam ser elaboradas de acordo com a necessidade e características de cada região do país. Portanto, concluiu-se que mesmo não apresentando as mesmas potencialidades, de outras áreas do Brasil, à diversificação do trabalho, representa para as unidades familiares pluriativas uma relevante alternativa para os agricultores familiares do município de Ribeirópolis/SE, percebendo que os mesmos apresentaram 
melhores condições de vida, quando são comparados com os agricultores dependentes apenas das atividades agrícolas.

Dessa maneira, foi evidenciado dois tipos de agricultores no espaço geográfico estudado; o primeiro apresenta-se muito mais dependente das atividades agrícolas, e mais dependente ainda das políticas de transferência de renda do Estado, por este, acabar sendo mais afetado pelas sazonalidades. O segundo tipo, apresentou-se (um pouco mais) dinâmico e empreendedor, buscando comercializar sua produção nas feiras livres dos municípios vizinhos, além de não serem caracterizados apenas por se dedicarem as atividades agrícolas. Com isso, são responsáveis pela formação de novos empreendimentos, os quais acabam diferenciando o espaço geográfico em que desenvolvem suas atividades.

Sendo assim, as unidades familiares em questão, apresentam necessidades diferentes, sendo que os agricultores menos dinâmicos necessitam de políticas públicas que propiciem a estes agricultores a saída da condição de miséria, na qual se encontram inseridos, fornecendo aos mesmos maiores benefícios do que apenas a política de transferência de renda, a qual acaba tornando-se importante na vida desses agricultores com a situação vivenciada, por ser a única fonte de renda garantida no final do mês, ao mesmo tempo gera a acomodação por parte dos mesmos, que em sua maioria não buscam reverter essa situação de miséria, a medida em que, não buscam caminhos ou até mesmo não possuem elementos para superar essas dificuldades.

O segundo grupo evidenciado, mesmo se tratando de um agricultor mais dinâmico, também necessita da presença do Estado, pois o mesmo recorre a um meio de vida caracterizado pela diversificação das rendas e o empreendedorismo, no entanto, não apresenta racionalidade econômica, e assim, o Estado atuaria profissionalizando esse agricultor, pois, uma das maiores dificuldades das unidades familiares pesquisadas é apresentar consciência da origem dos seus rendimentos.

Diante do cenário evidenciado sobre os desafios da agricultura familiar do muicipio de Ribeirópolis/SE, quatro pilares podem ser considerados como determinantes para o desenvolvimento das famílias em questão; políticas públicas, o apoio a produção comercialização agrícola, o incentivo a diversificação dos rendimentos e a participação social.

\section{Referências}

CANDIOTTO, L. Z. P. Pluriatividade: aspectos históricos e conceituais. Faz Ciência Francisco Beltrão, (UNIOESTE), v. 9, n. 10, p. 191-208, 2007.

CORRÊA, Roberto Lobato. Espaço um Conceito Chave. In: Geografia Conceitos e Temas. Bertrand Brasil. Rio de Janeiro, 2000.p. 15-48. 
FAJARDO, Sergio. Complexo agroindustrial, modernização da agricultura e participação das cooperativas agropecuárias no estado do Paraná. - revista on line caminhos da geografia. Uberlândia, v. 9, n. 27, set. 2008, p. 31-44.

GRAZIANO DA SILVA, José. A nova dinâmica da agricultura brasileira. Campinas: Unicamp-IE, 1996. 43-81.

O novo rural brasileiro. Nova Economia, v. 7, n. 1. Belo Horizonte- MG, 1997. p.

. Os desafios das Agriculturas Brasileiras. In: José Garcia Gasques, José Eustáquio Ribeiro Vieira Filho, Zander Navarro, (organizadores). A Agricultura Brasileira: desempenho, desafios e perspectivas / - Brasília: Ipea, 2010. p. 157-184.

. A industrialização e urbanização da agricultura brasileira. Versão de um trabalho apresentado ao projeto Iris/Desep-Cut fevereiro de 1993, p.1-9.

GRAZIANO DA SILVA, José. \& DEL GROSSI, M. E. A evolução da agricultura familiar e do agribusiness nos anos 90. In: RATTNER, H. (Org.) O Brasil no limiar do século XXI. São Paulo: EDUSP, p. 139-158, 2000.

LEITE, Sérgio Peite; KATO, Karina. Desafios dos processos de Gestão Social e proposições de Política. In: BARCELAR, Tânia,..[et.al] Gestão social dos territórios - Brasília: IICA, (Série Desenvolvimento Rural Sustentável: v.10), 227 p. 2009.

LOPES, Eliano Sérgio A. A pluriatividade na agricultura familiar do Estado de Sergipe. In: COSTA, J. E.; LOPES, S. A. (organizadores).Territórios Rurais e Agricultura Familiar no Nordeste. São Cristóvão: Editora UFS, 2009.

MARTINS, José de S. O sujeito oculto: ordem e transgressão na reforma agrária. Porto Alegre, RS: UFRGS, 2003.

MENDES, Marcelo Alves. Os (des) caminhos geográficos e a pluriatividade na agricultura familiar: aspectos teóricos e cotidianidade da agricultura familiar no Nordeste. São Paulo: Novas Edições Acadêmicas, 2014. v. 200. 261p.

NASCIMENTO, Carlos A. do. Pluriatividade, pobreza rural e políticas públicas. . (Tese de Doutorado). Campinas-SP: INSTITUTO DE ECONOMIA, UNICAMP/IE, 2005.

SCHNEIDER, Sergio. Agricultura familiar e desenvolvimento rural endógeno. Texto apresentado no Seminário de Desenvolvimento Rural - Tendências e debates contemporâneos. Realizado em 26 e 27 de maio de 2003, pela UFSM, em Santa Maria/RS/ Publicado em 2006.

As atividades rurais não agrícolas e as transformações do espaço rural: perspectivas recentes. Cuadernos de Desarrollo Rural. v. 1 n. 44, Bogotá, 2000, p. 11-40.

A importância da pluriatividade para as políticas públicas no Brasil. Revista Política Agrícola, Brasilia, Ano XVI, nº 3, Jul./Set./ 2007. 
Políticas públicas pluriatividade e desenvolvimento rural no Brasil. ANAIS, Políticas publicas y desarrolho rural, en el VII Congresso De La Asociación Latino Americana de Sociología Rural/ALASRU-20-24 de Novimbre del 2006- Quito, Equador, p. 1-20.

Situando o desenvolvimento rural no Brasil: o contexto e as questões em debate. Revista de Economia Política, São Paulo, v.30, n. 3, p. 511-531, julho-setembro/2010.

SEN, Amartya. Desenvolvimento como liberdade. Tradução Laura Teixeira Motta - São Paulo: Companhia de letras, 2010. 461 p. $4^{\text {a }}$ reimpressão.

WANDERLEY, Maria de N. B.O lugar dos rurais: o meio rural no Brasil moderno. Resumo dos Anais do XXXV Congresso Brasileiro de Economia e Sociologia Rural. Natal - RN, 1997. 